2021, Volume 16, ATEE 2020 - Winter Conference. Teacher Education for Promoting WellBeing in School. Suceava, 2020, pages: 397-409|

\section{Family and Kindergarten - the Partnership for Education}

\section{Elena REPCIUC (JUCAN) ${ }^{1}$}

\author{
1 Student at "Stefan cel Mare" \\ University from Suceava \\ jucancev@gmail.com
}

Abstract:This paper presents both theoretical and practical aspects of the significance of this kindergarten-family partnership with the mission to inform both teachers and parents about the importance of collaboration and to offer some suggestions by which we can make the communication between these two parts. The main objective underlying this paper is to study in detail the partnership between kindergarten and family and to analyze the reasons why this partnership is not fully realized in order to facilitate better communication between these two parties. The paper is structured in 3 chapters as follows: In the first chapter, called "The family environment and its educational value", the paper deals with topics such as: family a polysematic concept, family functions and educational styles in the family. In these second chapter, called "Kindergarten-family relationship, active and efficient partners in early education", the paper focuses on: the concept of educational partnership, collaboration between family and kindergarten - guarantee of school success, the opportunity of the educational partnership family-kindergarten, implementation of the family-kindergarten partnership and the importance of the kindergarten-family partnership in the formation and development of the personality of the preschool child. In the third chapter, which is the case study, "Comparison between the urban and rural areas, regarding the kindergarten-family partnership problem", the paper focuses on the level of involvement of parents and teachers in the issue of their involvement in the education of children. I will also analyze the difference between rural and urban areas regarding the problem of partnership and the involvement of parents and educators. The family must always be involved in the education of the child at home and at school. The partnership between family and kindergarten represents a strong collaborative relationship, with the belp of which we work in a team to establish the best methods of collaboration and education for the child. The kindergarten helps the child to develop psychically, physically and intellectually, leaving him with a bag of information that will help him in the future. Many may ask this question "What role does the family play in this process?". Well, the family gives the child the seven years at home, which are extremely important. Without the seven years at home, the educator cannot function as well as he or she would like. Without the help and involvement of the family in the relationship with the kindergarten, this process we call Partnership, would not exist. Also, in performing the processing and interpretation of the data from this research, the statistical method was used. After centralizing all the answers, I found the following facts: Parents are selective when it comes to their involvement in different activities within the kindergarten. The parents together with the teachers appreciate the importance of the partnership. In both urban and rural areas, we can say that there is openness and transparency when it comes to this partnership and between parents and teachers do not find communication problems.

Keywords: family, partnership, kindergarten, parent-school collaboration, effective communication, involvement.

How to cite: Repciuc (Jucan), E. (2021). Family and Kindergarten - the Partnership for Education. In O. Clipa (vol. ed.), Lumen Proceedings: Vol. 16. ATEE 2020 - Winter Conference. Teacher Education for Promoting WellBeing in School. Suceava, 2020 (pp. 397-409). Iasi, Romania: LUMEN Publishing House. https://doi.org/10.18662/lumproc/atee2020/27 


\section{Introduction}

We live in a world that is constantly changing, under pressure from parents, educators, business people, local communities and national governments, who work together to encourage systems that improve education, to ultimately help children develop. A plus that helps to achieve this goal is the involvement of the family in education, which has existed and has existed for generations.

The family must always be involved in the child's education both at home and at school. At home, parents can strengthen the learning process by being as active as possible in their child's life. By doing this, parents can motivate their children to learn and get involved as actively as possible in various activities and parents can expand their parenting skills.

All this is necessary because, as we well know, families in this modern society face a series of high demands, with economic problems that force parents to make difficult decisions and even work abroad. Very often we find the lack of communication between school and family which leads to new problems in terms of school practices.

That is why schools come to the aid of parents and try to solve these problems. And with the help of parents and this partnership between schools and families is trying to improve children's outcomes.

This paper presents both theoretical and practical aspects related to the significance of this partnership between kindergarten and family with the mission to inform both teachers and parents about the importance of this collaboration and to provide some suggestions through which we can communicate between these two parties.

The main objective underlying this paper is the detailed study of the partnership that takes place between kindergarten and family and the analysis of the reasons why this partnership is not fully realized in order to facilitate better communication between these two parties.

The paper is structured in 3 chapters as follows:

In the first chapter, called "Family environment and its educational value" the paper deals with topics such as: family-a polysemantic concept, family functions and educational styles in the family. 
In the second chapter, called "Kindergarten-family relationship, active and effective partners in early education" the paper focuses on: the concept of educational partnership, classifications and importance, kindergarten-educational factor, collaboration between family and kindergarten-guarantee of school success, ways to implement the familykindergarten partnership and the importance of the kindergarten-family partnership in the formation and development of the preschool child's personality.

In the third chapter, namely the case study, "Comparison between urban and rural areas regarding the issue of kindergarten-family partnership", the paper considers the level of involvement of parents and teachers in the issue of their involvement in children's education. I will also analyze the difference between rural and urban areas in terms of the issue of partnership and the involvement of parents and educators.

\subsection{Literature review}

The human community created by the family, allows the continuity of the human species and the evolution of society. The family also has several functions related to the harmonious growth, development and education of the child.

The functions of the family can be related to the functions of education, identified by Alina Stănculescu in the study "The role of education in socialization". The first function is: The function of child care involves "organized and permanent care from the family, nurseries, homes and other social institutions" (Stanculescu, 2010).

The child must be provided with the material and emotional resources necessary for optimal development, both in the family and in an institutionalized setting.

The child is a future member of society with full rights, who must know how to behave in society, to have a moral conduct "Through education, gradually, the child acquires the moral physiognomy of the time, learns to appreciate the deeds of others and his own, in relationship with an axiological system developed by society“(Stanculescu, 2010). 
It is essential to praise and encourage the child's real performance. But, many parents feed to the maximum the need for appreciation of the child, not realizing that it actually affects the structure of the child's ego. Instead of progressing, these children become addicted to appreciation and attention (Dowling et al., 2009).

"For us, parents or adults, you take care of a child over many categories or over time, which causes the constancy in allowing it to achieve a greater effect for each, even a creation and a difference. of us. It authorizes me to leave us, to separate from us, to make ourselves available, to face the risks and wonders of life."(Jacques Salome)

Kindergarten contributes to the development and education of the child being an extremely important factor. This component of the educational system is only one part of the education that the child must have. The family is a first and most important factor that contributes to the child's education.

These "educational agents", namely the family and the kindergarten, communicate and at the same time participate in the education of children and not in an easy way, but in a qualitative way. Nowadays we encounter extremely many problems and factors that stop or hinder this collaboration between the nursery and the family.

Contemporary family problems are much more demanding compared to 20-30 years ago. With these problems come the lack of time that the child should not be deprived of. The child needs his family, as a model in life, he needs to be taught, to be given advice, to be told what is good and what is bad, to be taught to behave and so on. For all these things, the involvement of the family is needed. Through this case study I aim to identify the problems that arise in terms of achieving the partnership between kindergarten and family and at the same time to make a comparison between rural and urban areas in terms of the level of involvement of both family and staff. teaching in the realization of the partnership. Thus, going to kindergarten expands its amount of interpersonal relationships and becomes the first experience of social life. Kindergarten and family become two distinct environments of influence. The child may spend more time in kindergarten than in the family. 
The binder that helps the preschool child to integrate into the social life of kindergarten is the game. The didactic game in a specialized framework "offers pre-schoolers numerous and varied opportunities to overcome the concrete stage and makes it easier and more pleasant to" climb "to the general and abstract" (Chiş et al., 2013). The game is very important on several levels, for cooperation, co-operation, but also to distinguish and integrate more easily in the community.

\section{Aims of research}

This case study presents both theoretical and practical aspects regarding the importance of partnership, family involvement, teachers.

Through this case study I want to offer certain directions and ways in which this partnership can be achieved effectively. An extremely important factor is transparency in terms of collaboration between kindergarten and family, this having beneficial effects in terms of both education and the child's development.

The main objective underlying this paper is the detailed study of the partnership between kindergarten and family and the analysis of the reasons why this partnership is not fully realized in order to facilitate better communication between these two parties.

The partnership between the family and the kindergarten represents a strong collaborative relationship, with the help of which we work in a team to establish the best methods of collaboration and education of the child.

In order to conduct this case study, we started from the following hypothesis:

"The active involvement of both family and teachers in the relationship that defines the partnership is different in rural areas than in urban areas, so the involvement of parents in rural areas is more active towards those in the urban environment".

Through this case study I aim to identify the problems that arise in terms of achieving the partnership between kindergarten and family and at the same time to make a comparison between rural and urban areas in terms of the level of involvement of both family and staff. teaching in the realization of the partnership. 


\subsection{Goals}

$>$ Highlighting the importance of the partnership between kindergarten and family;

$>$ Revealing the strengths following the creation of the kindergarten-family partnership;

$>$ Discovering the methods by which one can collaborate with the kindergarten;

> Highlighting the importance of educating the child in the family;

$>$ Analyzing family involvement in this partnership

$>$ Identifying the importance of partnership in order to develop the personality of the preschooler.

\subsection{Research objectives:}

Identifying the importance of family functions;

$>$ Identifying the relationships that take place between family and kindergarten within this partnership;

$>$ Encouraging parents regarding their involvement in the children's educational process;

$>$ Identifying conflicting states that may occur, and avoiding them for the good development of the child;

$>$ Highlighting the existence of transparency in the education process;

$>$ Highlighting the importance of a healthy environment for education.

\section{Research methods}

\subsection{Questionnaire-based survey}

To conduct this research, we chose the questionnaire method. We completed two questionnaires that were applied to both parents of children and teachers, of course those participating in the research. 


\subsection{The sample}

The tests were performed on a number of 120 subjects from the Kindergarten with normal program Solca and the Kindergarten with Normal Program Number 4 Piticot from Suceava, out of which 10 teachers and 110 children. The tests were performed for all existing groups, namely: small group, medium group and large group.

After the data were collected, they were processed for interpretation and to draw certain conclusions. From the statistical techniques through which you can perform the analysis of the data of some questionnaires, we chose the bar graphs, ie the graphical representation of the results.

\subsection{Method of interpreting the results - Statistical method}

The data were interpreted step by step as follows:

First, the completion of the questionnaires by the study participants;

Second, data collection;

Third, the centralization of the questionnaires in the SPSS statistical program;

Finally, the interpretation of the data using the analysis made by the SPSS statistical program.

Factual data about the partnership between kindergarten and family

The most common problems are the following:

- the existence of barriers that prevent the efficient functioning of this partnership between kindergarten and family;

- lack of clear distribution of roles and responsibilities between partners: kindergarten-family-child;

- transparency in decision-making, as well as lack of information from both teachers and the family;

- modest training of teachers.

The main obstacles that prevent the realization of the partnership between kindergarten and family are:

- migration of parents, or a parent;

- lack of time;

- lack of methodological support regarding the "education" of parents; 
- lack of initiative;

- unfavourable psychological climate in the family;

- lack of pratenery models, etc.

\section{Results}

\subsection{Questionnaires applied to parents}
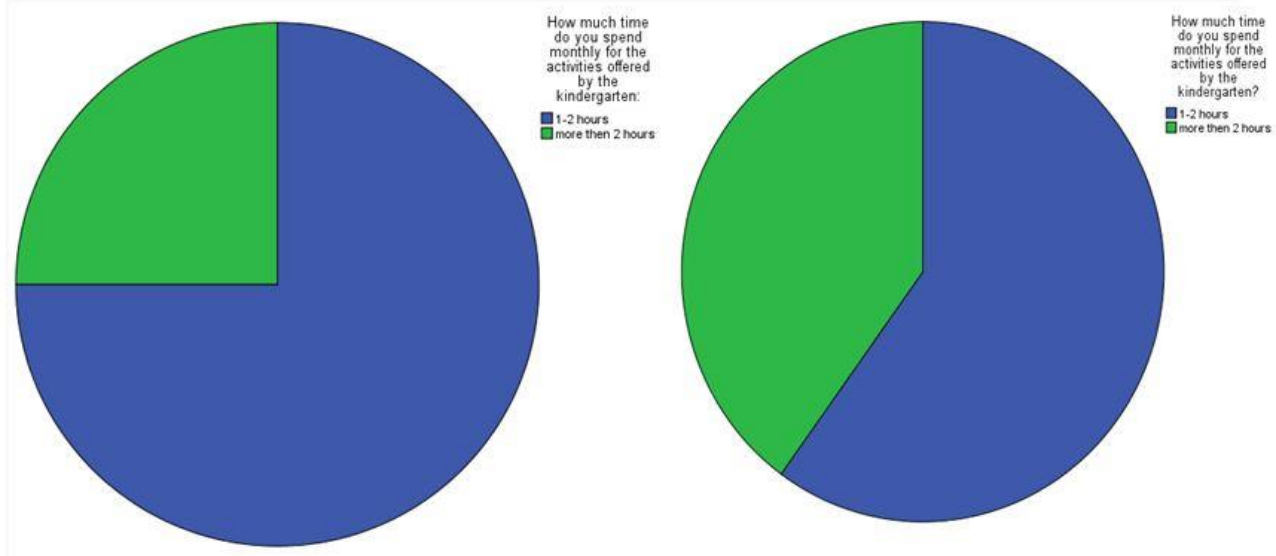

Fig. 1. The time that parents give to collaboration

Urban environment/Rural environment

Regarding the involvement of parents in the activities carried out in the kindergarten and the allocation of time, the results in urban areas do not differ much from those in rural areas.

In a percentage of about $33 \%$, parents in urban areas give to the activities offered by kindergarten, on average 1-2 hours. Compared to the urban environment, the parents from the rural area give in a percentage of approximately $16 \%, 1-2$ hours to the activities offered by the kindergarten, which represents half of the time that those from the urban area give. In extremely small percentages, both in urban and rural areas, parents give either less than an hour to activities in kindergarten or as needed, they say.

Regarding the importance of kindergarten in the child's life and if the parents consider the kindergarten a real partner in the child's education process, both in urban and rural areas we have approximately similar results. 


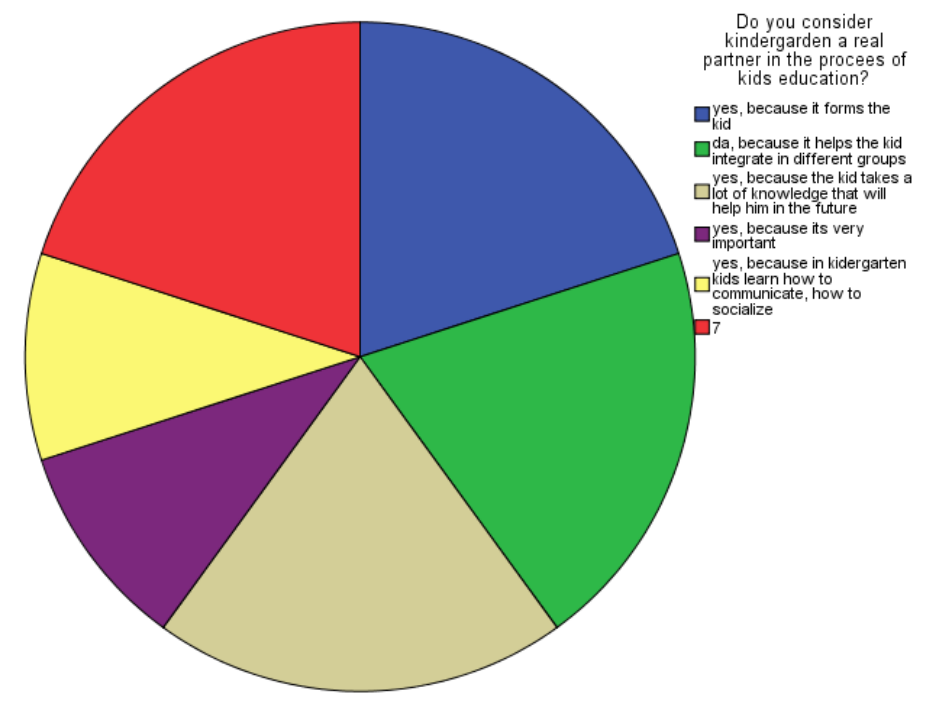

Fig. 2. The importance of kindergarten in the child's life (urban)

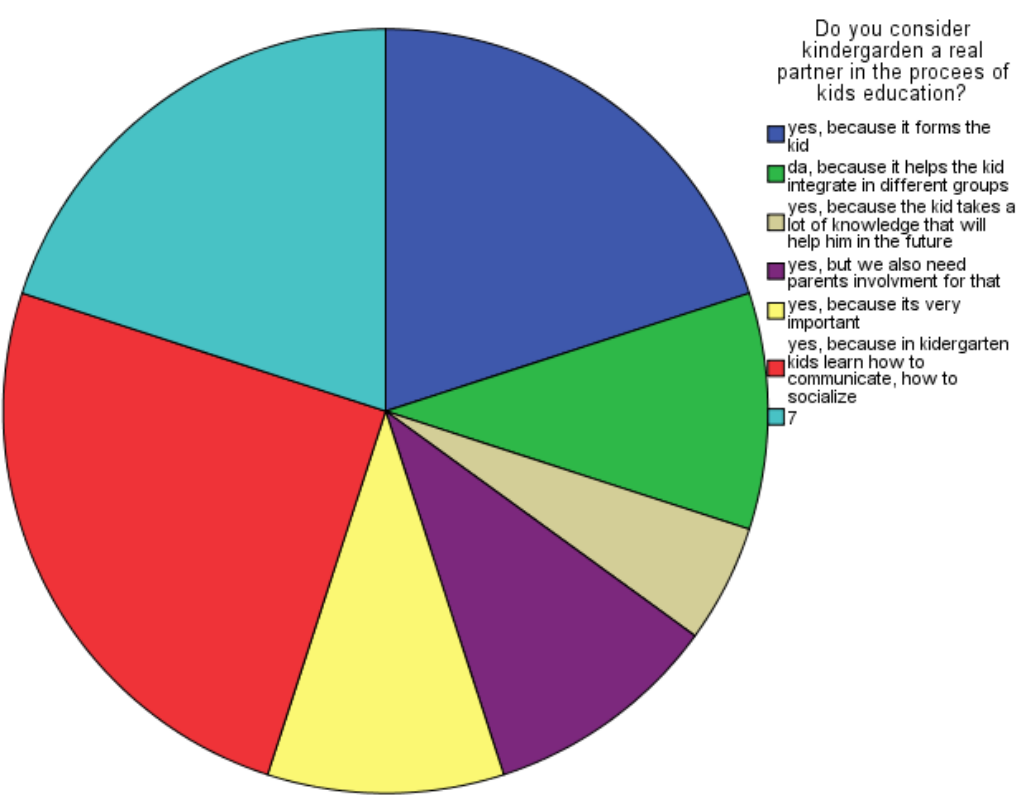

Fig. 2. The importance of kindergarten in the child's life (rural)

\subsection{Questionnaire applied to teachers}



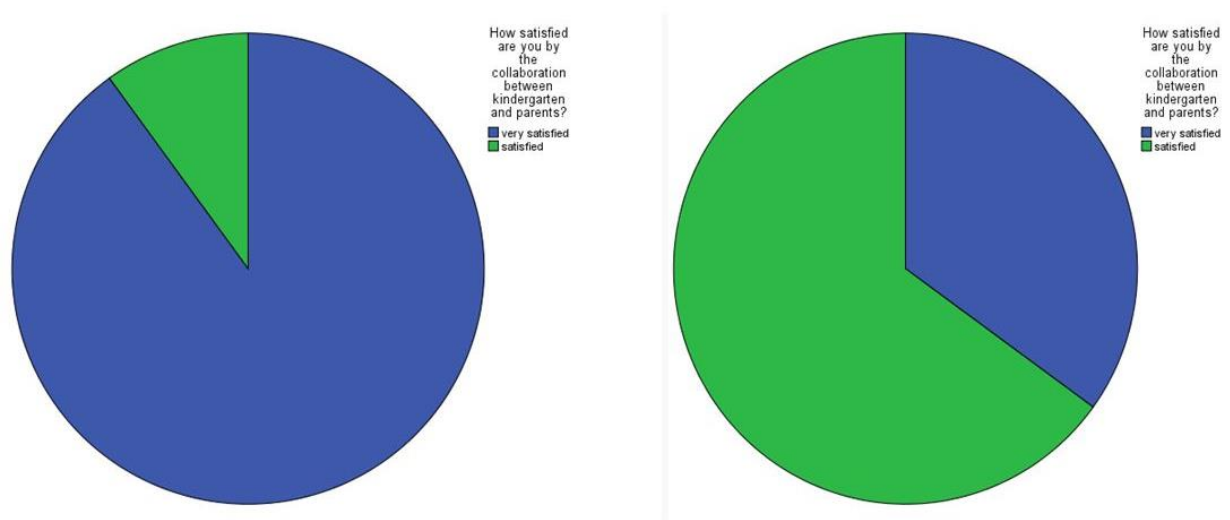

Fig. 3. Acknowledgment to the kindergarten-family partnership

Urban environment/Rural environment

If in the urban area we observe a percentage of approximately $90 \%$ of the surveyed teachers who consider that they are very satisfied with this collaboration, in the rural area we have only a percentage of $40 \%$ who consider this. What we can deduce is that in urban areas, teachers are twice as satisfied as teachers in rural areas, in terms of the issue of kindergartenfamily collaboration.
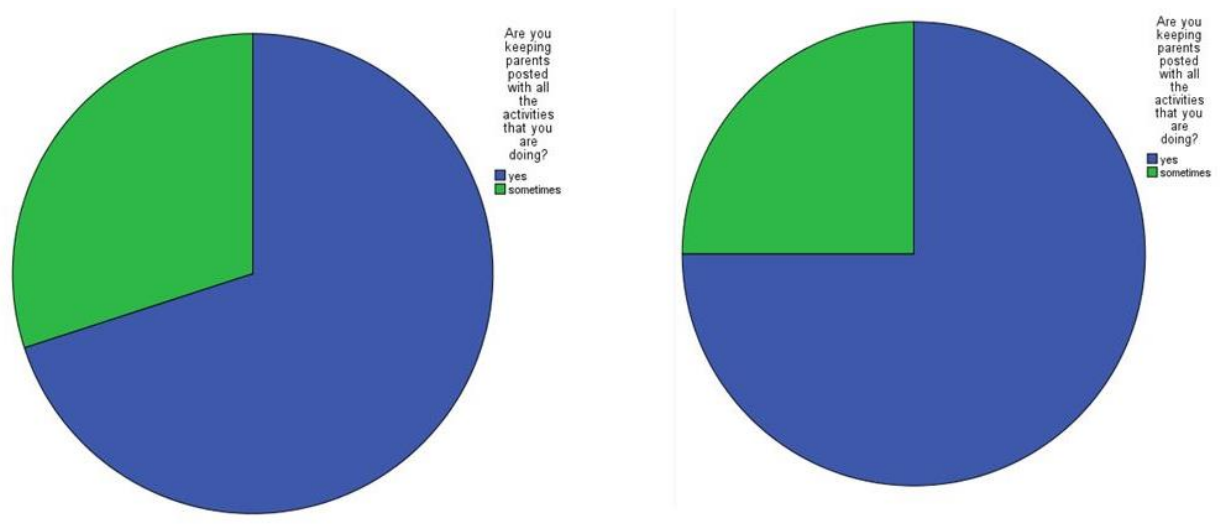

Fig 4. Informing parents about kindergarten activities Urban environment/Rural environment

The results gathered after the teachers' questioning regarding the information of the parents about all the activities that take place within the group during the days, weeks, months, year were encouraging. There is, not a big difference in teachers' responses. In both urban and rural areas, 
teachers gave approximately the same answers, answering "yes" and "sometimes".

\section{Discussions}

Following the introduction of data in the SPSS statistical program and the centralization of results, the initial hypothesis was partially confirmed as the partnership between kindergarten and family in rural and urban areas is different in urban areas than in rural areas, but only from certain points of view. From a certain point of view, in the rural area we find more involvement with the urban environment and also in the urban area with respect to the rural area.

Following the centralization of all the answers, we found the following facts:

- parents in rural areas give more involvement to the activities offered by kindergarten than those in urban areas;

- in both urban and rural areas, we can say that there is openness and transparency when it comes to this partnership;

- parents together with teachers appreciate the importance of partnership.

- ways of caring can help the collaboration between kindergarten and family:

- putting into circulation the parents in connection with the importance in terms of partnership, beneficiaries for children;

- parental involvement in activating care operations is more open;

\section{Conclusions}

Even if for some the kindergarten is described only as a place where children go and play, it is not so at all. In kindergarten, the child learns many things that will be useful both in social and personal life. Kindergarten helps the child to develop mentally, physically and intellectually, leaving him with a wealth of information that will help him in the future.

This age of preschool is extremely important because during this period the child develops a lot. During this stage the child begins to ask 
questions, to be curious, to wait for answers, to be curious about certain things, to observe the world around him with different eyes. During this period, in kindergarten, the child learns how to speak, write, read and count. In this kindergarten environment, the child begins to interact with others and thus learns and develops this concept of relationship. In addition to these things, the child also learns how to behave, how to talk to those around him, to respect, to ask nicely, to thank, etc.

Many may ask, "What is the role of the family in this process?" Well, the family gives the child the seven years at home, which are extremely important. Without the seven years at home, the educator cannot function as well as he would like. Without the help and involvement of the family in the relationship with the kindergarten, this process that we call Partnership, would no longer exist.

In order to conduct this case study, we started from the following hypothesis: "The active involvement of both family and teachers in the relationship that defines the partnership is different in rural areas than in urban areas, so the involvement of parents in rural areas is more active compared to those in urban areas. "

The parents are selective when it comes to their involvement in various activities in kindergarten and parents together with teachers appreciate the importance of partnership. Between parents and teachers, we do not find problems in terms of communication. There is openness on the part of parents, say teachers. There are some difficulties in communicating with parents and teachers appreciate the partnership as very important.

Ways we can improve this collaboration between kindergarten and family:

informing the parents about the importance of this partnership, the beneficiaries being their children;

involvement of parents in activities where they are more open;

explaining to parents all the benefits that this partnership has;

planning all activities depending on the availability of parents.

Even if on the whole the parents are of the opinion that this partnership is going as it should, the teachers do not share the same opinion. 
Parental involvement is needed because the sustainability of this partnership is pursued. Parents should be more involved in this partnership.

For this partnership to work, we must take all the problems and solve them step by step. With the involvement of both parents and teachers, this partnership can be achieved and remedied.

"Those who educate children are worthy of more honour than those who give them life; that is why, in addition to life, you give children the art of living well, educating them."

\section{References}

Chiş, V., Catalano, H., \& Alexandru. (2013). Pedagogiile alternative: conceptualizări, dezvoltări curriculare, exemple de bune practici [Alternative pedagogies: conceptualizations, curricular developments, examples of good practices]. Eikon Publishing House.

Dowling, C. B., Slep, A. M. S., \& O’Leary, S. G. (2009). Understanding Preemptive Parenting: Relations With Toddlers' Misbehavior, Overreactive and Lax Discipline, and Praise. Journal of Clinical Child \& Adolescent Psychology, 38(6), 850-857. https://doi.org/10.1080/15374410903258983

Stanculescu, A. (2010). Rolul educatiei in socializare. https://promanagement.ro/alina-stanculescu/ 